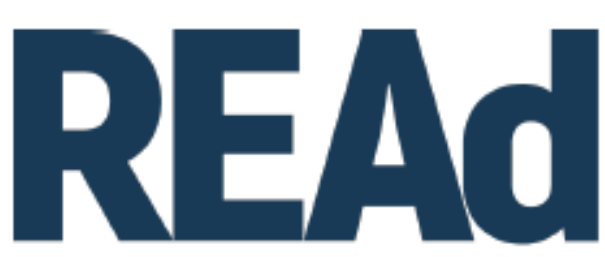

Revista Eletrônica de Administração

\title{
EFEITO DISPOSIÇÃO EM INVESTIMENTOS: INVESTIDORES INDIVIDUAIS E INSTITUCIONAIS AGEM DE MANEIRA DIFERENTE? ${ }^{1}$
}

\author{
Fernanda Holdorf Lopez ${ }^{2}$ \\ Wlademir Ribeiro Prates ${ }^{3}$ \\ Vanessa Martins Valcanover ${ }^{4}$ \\ Newton Carneiro Affonso da Costa $\mathbf{J r}^{5}$
}

http://dx.doi.org/10.1590/1413-2311.316.101702

\section{RESUMO}

Muitos agentes atuantes nas bolsas de valores são relutantes em realizar perdas e têm maior facilidade em realizar ganhos, comportamento chamado de "efeito disposição". Tais agentes podem ser individuais ou institucionais, esses últimos considerados mais racionais em suas tomadas de decisão. Assim, este artigo buscou analisar se existem diferenças quanto à presença do efeito disposição na tomada de decisões financeiras entre investidores individuais e institucionais. A amostra compreendeu transações realizadas por investidores individuais e institucionais, entre janeiro de 2012 e 31 de outubro de 2014, com dados reais de três ações obtidos na bolsa de valores brasileira, sendo aplicada uma metodologia específica para detectar o efeito disposição. Resultados mostraram que o efeito disposição está presente em todas as

\footnotetext{
${ }^{1}$ Recebido em 6/4/2020, aceito em 20/10/2020.

${ }^{2}$ Universidade Federal de Santa Catarina - Departamentos de Economia e Relações Internacionais; Florianópolis - SC (Brasil); http://orcid.org/0000-0002-1282-2891; fernandaholdorf@ gmail.com.

${ }^{3}$ Universidade Federal de Santa Catarina - Programa de Pós-graduação em Administração; Florianópolis - SC (Brasil); http://orcid.org/0000-0002-9274-5784; wrprates@yahoo.com.

${ }^{4}$ Universidade Federal de Santa Catarina - Programa de Pós-graduação em Administração; Florianópolis - SC (Brasil); http://orcid.org/0000-0001-7576-0205; vanessamvalcanover@ gmail.com.

${ }^{5}$ Universidade Federal de Santa Catarina - Programa de Pós-graduação em Administração; Florianópolis - SC (Brasil); http://orcid.org/0000-0001-7723-2676; ncacjr@gmail.com
} 
análises para os investidores individuais e em apenas algumas análises para os investidores institucionais, sendo mais forte para os investidores individuais. Isto indica que os investidores individuais são mais enviesados pelo efeito disposição do que os investidores institucionais. Ademais, a média dos retornos das aplicações dos investidores institucionais foi maior do que as realizadas por investidores individuais, mostrando que os investidores institucionais alcançam melhores retornos em suas aplicações.

Palavras-chave: Efeito disposição. Bolsa de valores. Investidores individuais. Investidores institucionais. Tomada de decisão.

\section{DISPOSITION EFFECT IN INVESTMENTS: DOES INDIVIDUAL AND INSTITUTIONAL INVESTORS BEHAVE DIFFERENTLY?}

Many of the agents trading in stock exchanges are reluctant in realizing losses, and find it easier to make gains, a behavior called "disposition effect". Those agents can be individual or institutional, the latter being considered more rational in their decision-making. Thus, this paper aimed to analyze whether there are differences regarding the presence of the disposition effect in the financial decision-making between individual and institutional investors. The sample comprised transactions carried out by individual and institutional investors, from January 2012 to October 31,2014, with real data from three assets obtained in the Brazilian stock exchange, using a specific methodology to detect the disposition effect. Results showed that the disposition effect is present in all analyses for individual investors and in only a few analyses for institutional investors, being stronger for individual investors. This indicates that individual investors are more biased by the disposition effect, while institutional investors are less biased. Furthermore, the average returns on institutional investors' investments were higher than those obtained by individual investors, showing that institutional investors achieve better returns on their investments.

Keywords: Disposition effect. Stock Exchange. Individual investors. Institutional investors. Decision-making.

\section{EFECTO DE DISPOSICIÓN EN INVERSIONES: ¿LOS INVERSORES INDIVIDUALES E INSTITUCIONALES LO HACEN DIFERENTEMENTE?}

Muchos de los agentes que operan en bolsas de valores son reacios a generar pérdidas y les resulta más fácil obtener ganancias, comportamiento llamado "efecto de disposición". Dichos 
agentes pueden ser individuales o institucionales, estos últimos considerados más racionales en su toma de decisiones. Así, este artículo buscaba analizar si existen diferencias con respecto a la presencia del efecto de disposición en la toma de decisiones financieras entre inversores individuales e institucionales. La muestra comprendió transacciones realizadas por inversores individuales e institucionales, entre enero 2012 y 31 octubre 2014, con datos reales de tres acciones obtenidas en la bolsa de valores Brasileña, utilizando una metodología específica para detectar el efecto de disposición. Los resultados mostraron que el efecto de disposición está presente en todos los análisis para inversionistas individuales y solo en unos pocos análisis para inversionistas institucionales, siendo más fuerte para inversionistas individuales. Esto indica que los inversores individuales están más predispuestos por el efecto de disposición, mientras que los inversores institucionales están menos predispuestos. Además, los rendimientos medios de las inversiones de los inversores institucionales fueron más altos que los obtenidos por los inversores individuales, lo que demuestra que los inversores institucionales obtienen mejores rendimientos de sus inversiones.

Palabras clave: Efecto de disposición. Bolsa de valores. Inversores individuales. Inversores institucionales. Toma de decisiones.

\section{INTRODUÇÃO}

O comportamento dos agentes econômicos é tema de estudo de diversos pesquisadores visto sua influência nas ações econômicas, principalmente em relação à tomada de decisões no mercado financeiro. Na escola neoclássica da economia, a Teoria da Utilidade Esperada (TUE), apresentada por Edwards (1954), von Neumann e Morgenstern (1953) e Bernoulli (1954), estabelece que os agentes econômicos agem de maneira racional, isto é, aprimoram suas escolhas de forma a obter a maior utilidade esperada e têm amplas informações sobre o mercado.

No entanto, a tomada de decisões na área de investimentos em bolsa de valores envolve um grande número de variáveis, sendo um cenário complexo e incerto e impedindo que os agentes tomem decisões perfeitamente racionais. Ainda, pesquisas têm revelado o importante papel das emoções no processo de tomada de decisão financeira. Tais questões levaram ao surgimento das finanças comportamentais, na qual pesquisadores como Kahnemann e Tversky (1979) realizaram análises do comportamento de indivíduos em diferentes situações envolvendo risco e verificaram que este não pode ser plenamente explicado pela TUE. Um 
exemplo está no fato desses autores apresentarem, em seus experimentos, uma mesma proposta de maneiras distintas aos indivíduos, os quais tomaram decisões diferentes de acordo com a forma de apresentação da problemática.

Ao analisarem o comportamento dos agentes econômicos na tomada de decisão em bolsa, Shefrin e Statman (1985) concluíram que muitos destes são mais relutantes em realizar perdas e têm maior facilidade em realizar ganhos, comportamento denominado de "efeito disposição". Agentes sob este efeito retêm por um período maior uma ação "perdedora", cujo valor está em queda, evitando o momento da venda e a sensação de ser lesado. O inverso ocorre com as ações "vencedoras", de valor em ascensão: os agentes as vendem depressa para terem a sensação de êxito e lucro. Autores como Grinblatt e Keloharju (2001), Chen et al. (2007), Bogea e Barros (2008), Ploner (2017) e Deaves et al. (2018) também relataram a existência do efeito disposição em suas amostras de pesquisa.

No mercado financeiro, os agentes econômicos atuantes podem ser individuais ou institucionais (fundos mútuos, clubes de investimentos, bancos de investimentos, dentre outros). Em relação às diferenças de comportamento entre esses, Shapira e Venezia (2001) verificaram, em uma amostra de 4.300 investidores na Bolsa de Tel Aviv, em Israel, que os investidores institucionais são mais inclinados a decisões racionais, por terem mais informações que os investidores individuais e possuírem inúmeras ferramentas analíticas para suporte à tomada de decisões. A partir disso, é possível esperar que o efeito disposição se manifeste em graus diferentes para os investidores individuais e institucionais.

Assim, o presente artigo tem como objetivo analisar se existem diferenças quanto à presença do efeito disposição na tomada de decisões financeiras entre investidores individuais e institucionais atuantes na bolsa de valores brasileira. A amostra utilizada compreendeu as transações realizadas por investidores individuais e institucionais, esses representados por fundos mútuos, no período de janeiro de 2012 a 31 de outubro de 2014, com dados reais obtidos na bolsa de valores brasileira (B3, antiga BM\&FBOVESPA). Como objetivos específicos, busca-se: a) verificar a existência do efeito disposição nas transações analisadas; b) identificar quais são as diferenças entre o comportamento do investidor individual e institucional quanto ao efeito disposição na tomada de decisões financeiras; e c) investigar se há diferença em relação ao desempenho dos resultados alcançados pelos investidores individuais e institucionais.

Uma vez que estudos demostraram a existência de diferenças no comportamento de investidores individuais e institucionais, manifesta-se o interesse em verificar o comportamento destes agentes na bolsa de valores brasileira. Pesquisas como a de Cici (2012) mostram que o 
efeito disposição interfere nas transações de alguns fundos de investimento, mas em menor intensidade do que afeta investidores individuais, e Shapira e Venezia (2001) observaram que investidores institucionais têm maior predisposição a decisões racionais.

Desta forma, na presente pesquisa foi estudado o comportamento de investidores pessoa física e de fundos mútuos em três ações específicas, a partir da coleta de dados reais da bolsa. Trabalhos que trataram do efeito disposição no Brasil, como o de Da Costa et al. (2007), Bogea e Barros (2008) e Ribeiro, Carvalho Jr. e Da Rocha (2015), utilizaram do ambiente experimental para analisar a presença do efeito disposição no comportamento de indivíduos. De maneira contrária, Tizziani et al. (2010) abordaram o efeito disposição a partir de dados da bolsa de valores, porém consideraram apenas investidores institucionais. Isso demonstra a relevância da presente pesquisa, visto que poucos são os estudos desta natureza que utilizam dados reais da bolsa de valores para analisar o efeito disposição no mercado de capitais brasileiro, análise que permite um melhor entendimento do funcionamento do mercado como um todo.

Ademais, destaca-se o grande aumento no número de investidores na bolsa de valores brasileira nos últimos anos, sendo que o número de investidores pessoa física passou de 116.914 em 2004 para 564.116 em 2014 e mais de 3 milhões em 2020 (B3, 2020). Segundo Sakate (2020), o valor negociado diretamente por investidores pessoa física alcançou em 2020 o valor de R 121 bilhões, ficando muito próximo do valor investido por investidores institucionais, de R \$ 123 bilhões, salientando a importância de analisar a possível diferença dos dois grupos frente ao efeito disposição, já que são responsáveis pela movimentação de grandes quantias em dinheiro no mercado acionário do país.

O artigo está organizado em cinco seções, sendo a primeira delas esta introdução. $\mathrm{Na}$ segunda seção, tem-se a fundamentação teórica, que abrange os temas de finanças comportamentais, efeito disposição e diferenças entre investidores individuais e institucionais. Já na terceira seção, é apresentado o método de pesquisa, e, na quarta seção, a análise dos resultados. Por fim, na quinta seção são expostas as considerações finais do estudo.

\section{O EFEITO DISPOSIÇÃO E O COMPORTAMENTO DOS INVESTIDORES}

O efeito disposição consiste em um viés comportamental, fundamentando-se na objeção dos agentes em realizarem perdas. Neste sentido, a pesquisa de Shefrin e Statman (1985) apresentou uma estrutura teórica que busca explicar a presença do efeito, propondo quatro elementos que o explicam: a teoria da perspectiva, a contabilidade mental, a aversão ao arrependimento e o auto-controle. Mais adiante, Odean (1998) expôs o viés da reversão à média, 
outro possível elemento considerado para o entendimento do efeito disposição. Tais elementos são abordados na sequência, e, posteriormente, estabelece-se a relação do efeito disposição com os investidores individuais e institucionais.

\subsection{OS ELEMENTOS EXPLICATIVOS DO EFEITO DISPOSIÇÃO}

O primeiro elemento que apresenta relação, de maneira direta, com o efeito disposição é a teoria da perspectiva, evidenciada por Kahneman e Tversky (1979), a qual argumenta que os agentes, em seu processo de tomada de decisão, primeiro organizam suas escolhas em termos de perdas ou ganhos potenciais relativos a um determinado ponto de referência. Em seguida, utilizam uma função de avaliação em forma de $S$, sendo côncava no domínio dos ganhos e convexa no domínio das perdas, retratando a aversão ao risco na região dos ganhos e propensão ao risco na região das perdas.

Ademais, percebe-se que os investidores tendem a manter ações perdedoras, já que a dor de uma perda adicional é menor do que o prazer de eventualmente reaver o preço da compra. Por outro lado, os agentes tendem a vender ações vencedoras, visto que o prazer de um ganho adicional é menor do que a dor do preço da ação retornar ao preço da compra (WEBER; CAMERER, 1998).

Na sequência, a noção de contabilidade mental também se mostra como um elemento explicativo do efeito disposição. Introduzida por Thaler (1985), consiste na crença de que existe uma tendência por parte dos tomadores de decisão em separar os tipos de situação de risco que experienciam em diferentes contas mentais. Após essa separação, empregam o conceito da teoria da perspectiva, não considerando a relação entre tais situações. Conforme o autor, os tomadores de decisões apresentam dificuldade em fechar contas mentais com perdas, visto que o fechamento expressa a realização da perda; assim, os investidores tendem a conservar ativos perdedores em seus portfólios.

Outrossim, Shefrin e Statman (1985) sugeriram a aversão ao arrependimento como uma explicação ao efeito disposição, tema que também vem sendo trabalhado nas finanças comportamentais (MUERMANN; VOLKMAN, 2006). De acordo com Muermann e Volkman (2006), na hipótese do orgulho e do arrependimento por parte dos agentes, quando um investidor realizar a compra de uma ação e esta vir a sofrer depreciação, ele se arrependerá, e, como têm esperança de que a ação terá ganho no futuro, o investidor a mantêm em sua carteira. Em contrapartida, se a ação tiver valorização em seu preço, o investidor efetuará a venda pelo orgulho de conseguir retorno positivo. Desta forma, a busca pelo orgulho e a aversão ao 
arrependimento fazem com que o indivíduo apresente uma disposição para realizar ganhos e adiar perdas (MUERMANN; VOLKMAN, 2006).

Já o conceito de autocontrole, mais um elemento explicativo do efeito disposição, foi explicado por Thaler e Shefrin (1981), o qual se depara com os conflitos pessoais dos indivíduos, entre seus lados racional e emocional. Os autores recorreram ao exemplo da gestão de conflitos entre gestores e proprietários de uma empresa, na qual é indispensável o uso de mecanismos de alinhamento para mitigar os conflitos entre as partes, constatando que o mesmo também é necessário para se ter autocontrole no processo de tomada de decisões. Em sua relação com o efeito disposição, Shefrin e Statman (1985) propuseram a adoção da ordem de stop loss, instrumento que executa uma ordem imediata de venda caso determinada ação atinja um preço abaixo do estabelecido pelo agente executor. Esta ferramenta está vinculada à dificuldade dos indivíduos em realizarem perdas, sendo adotada também para minimizar possíveis perdas.

Por fim, tem-se a reversão à media, apresentada por Odean (1998), a qual consiste na crença de que ativos que estão expressivamente depreciados podem vir a se valorizar, enquanto ativos com apreciação significativa podem se depreciar; assim, os preços dos ativos tendem a se dirigir para um valor médio. De acordo com Andreassen (1998), os investidores são influenciados pela oscilação dos ativos e pela maneira como tal oscilação ocorre, e, em seu estudo, verificou que os participantes que tomavam suas decisões baseados na variação percentual eram propensos a seguir uma estratégia apoiada na reversão à média.

Conforme Odean (1998), os indivíduos podem optar por manter as ações perdedoras e vender as vencedoras, não devido à relutância em se desfazer das perdedoras, mas porque presumem que as perdedoras de hoje irão ultrapassar as vencedoras de hoje. O autor afirma que, se o retorno esperado da perdedora exceder o retorno esperado da vencedora, a decisão do investidor será racional e justificável; no entanto, se o retorno esperado da ação perdedora não ultrapassar o da vencedora, e o indivíduo persistir nesta crença, sua decisão será irracional e injustificável.

Buscando se certificar desta hipótese, Odean (1998) conduziu uma pesquisa no mercado acionário norte-americano, constatando que ações vencedoras apresentaram um retorno anormal médio de 3,4\% em relação às ações perdedoras mantidas em um longo período subsequente de doze meses. Desta forma, pode-se afirmar que a atitude dos investidores em reter ações perdedoras em um portfólio, com a esperança de que essas venham a ser mais rentáveis que as vencedoras no futuro, é irracional. 


\subsection{AS DIFERENÇAS ENTRE INVESTIDORES INDIVIDUAIS E INSTITUCIONAIS}

As finanças comportamentais abrangem um extenso campo de pesquisa que, conforme Shiller (2003), busca analisar as finanças sob a ótica das ciências sociais, o que inclui a psicologia e a sociologia. Brav e Heaton (2006) argumentam que, para as finanças comportamentais, a ineficiência dos mercados pode ocorrer visto que os investidores irracionais, chamados de noise traders, são capazes de levar os preços para além dos níveis racionais por determinado período de tempo. Neste ponto, começam a ser consideradas as possíveis diferenças de comportamento entre os tipos de investidores que atuam no mercado.

Ao realizarem um estudo na Bolsa de Tel Aviv, que incluiu 4.300 investidores, Shapira e Venezia (2001) observaram que investidores institucionais são mais propensos a tomarem decisões consideradas racionais, uma vez que são mais bem informados do que os investidores individuais, além de terem à sua disposição várias ferramentas analíticas para apoio à tomada de decisões, as quais não são de fácil acesso aos investidores individuais. No entanto, outros autores encontraram resultados opostos. Por exemplo, Locke e Mann (2000) desenvolveram uma pesquisa com investidores institucionais no mercado de commodities da Chicago Mercantile Exchange (CME), compreendendo dados do ano de 1995, e concluíram que investidores institucionais também sofrem do efeito disposição. Os autores observaram que operadores com resultados ruins mantiveram ativos perdedores por um prazo maior, ao passo que operadores com rentabilidades melhores retiveram ações perdedoras por menor tempo.

Ademais, Cici (2005) demostrou que o efeito disposição afeta as transações de alguns fundos de investimento, no entanto, em menor nível do que afeta investidores individuais. Essa pesquisa considerou o mercado americano, o qual possui legislação de impostos benéfica às vendas no último trimestre do ano, fator que se mostrou relevante para a estimação do grau do efeito disposição. Ainda, obteve-se que tal viés comportamental é negativamente relacionado com o desempenho dos fundos.

O mercado brasileiro também foi alvo de análise frente ao efeito disposição. Neste sentido, Tizziani et al. (2010) analisaram as ações que integravam o índice IbrX-50, no período de novembro de 2003 a fevereiro de 2008, e perceberam que o efeito disposição se manifestou apenas com base no número de transações mensais feitas pelos fundos de investimento, para o cômputo do percentual de ganhos e perdas realizadas. Posteriormente, os autores segmentaram a base em fundos de varejo e fundos destinados a investimentos qualificados, situação em que não se pôde verificar a presença do efeito disposição, quando se considerou o volume monetário transacionado como fator de ponderação de ganhos e perdas realizadas. Com dados mais atuais, 
de 2009 a 2014, Rodrigues (2016) também verificou a presença do efeito disposição em gestores brasileiros de fundos de investimento em ações.

Prates, Da Costa Jr. e Santos (2019) analisaram a propensão à venda de investidores brasileiros e verificaram que investidores pessoa física são mais propensos ao efeito disposição, ao passo que investidores institucionais não exibiram um comportamento condizente com o efeito. Também no Brasil, Da Costa Jr. et al. (2013) analisaram o efeito disposição em investidores experientes e inexperientes, através de um experimento que simulou o mercado de ações, e concluíram que investidores inexperientes apresentaram maior efeito disposição. Por fim, a revisão de literatura de Zahera e Bansal (2019) apontou que investidores individuais são amplamente suscetíveis ao efeito disposição, e que variáveis de gênero, idade e experiência também levam à ocorrência do efeito. Por outro lado, os investidores institucionais e os gestores de fundos de investimento podem ou não ser afetados pelo efeito disposição, mostrando que ainda não há um consenso na literatura.

\section{MÉTODO DE PESQUISA}

De forma a atender ao objetivo da pesquisa, foi utilizada uma amostra de dados reais coletados na bolsa de valores brasileira, abrangendo o período de 2 de janeiro de 2012 até 31 de outubro de 2014. Esta amostra faz parte de uma base de dados adquirida junto à bolsa e disponibilizada pelo grupo de pesquisa "Finanças e Análise de Investimentos", cadastrado no CNPQ, da Universidade Federal de Santa Catarina. Foi preservado o sigilo dos dados pessoais dos investidores, tendo sido criados códigos de identificação para cada investidor, distinguindo pessoas físicas de investidores institucionais.

Inicialmente, a amostra englobava 21.896 opções de investidores e três ações diferentes, BBDC4 (Bradesco, Banco privado do Brasil), ABEV3 (AMBEV, Companhia de Bebidas das Américas) e LAME4 (Lojas Americanas, Rede brasileira do setor de varejo). Desses dados, foram selecionados 30 investidores individuais e 30 investidores institucionais do segmento de fundos mútuos para cada uma das três ações. A seleção dos investidores se deu de maneira aleatória pela função "Amostragem” do Software Microsoft Excel.

Para operar e selecionar os dados corretos entre todas as informações presentes na base, foi utilizado um algoritmo desenvolvido em linguagem Python e SQL, o qual também considera todos os rendimentos realizados no período para estabelecer o resultado final do retorno das operações realizadas, tais como bonificações, dividendos, desdobramentos, grupamentos, dentre outros. O resumo da amostra final da pesquisa é apresentado na Tabela 1.

REAd | Porto Alegre - Vol. 27 - N.o 1 - Janeiro / Abril 2021 - p. 210-231. 
Tabela 1 - Amostra de dados (número de transações) utilizada (período 02/01/2012 a 31/10/2014)

\begin{tabular}{l|c|c|c}
\hline \multirow{2}{*}{30 investidores de cada grupo } & \multicolumn{3}{|c}{ Quantidade de transações por ação no período } \\
\cline { 2 - 4 } & BBDC4 & ABEV3 & LAME4 \\
\hline Investidor individual & 2675 & 2876 & 1601 \\
Investidor institucional & 30772 & 14662 & 75237 \\
\hline
\end{tabular}

Pela Tabela 1, percebe-se que a ação LAME4 obteve o maior número de transações no período. Na sequência, a respeito da metodologia utilizada, empregou-se a mesma introduzida por Odean (1998), o qual afirmou que é necessário examinar a proporção de perdas e ganhos realizados para apurar a existência do efeito disposição. Conforme o autor, não se deve apenas comparar se os investidores venderam mais ações vencedoras do que perdedoras, pois isso levaria a um resultado que estaria simplesmente refletindo as tendências do mercado. Assim, deve-se verificar com qual frequência os investidores vendem ações vencedoras e perdedoras relativo à oportunidade de vender em cada um dos dois tipos de situação, ganhos e perdas.

Por conseguinte, segundo Odean (1998), foi comparada a proporção da soma de ganhos realizados e ganhos não realizados com a proporção da soma de perdas realizadas e perdas não realizadas, variáveis denominadas de proporção de ganhos realizados (PGR) e proporção de perdas realizadas (PPR). Subtraindo-se a PPR da PGR, obtêm-se o chamado coeficiente de disposição (CD), cujo resultado positivo aponta a presença do efeito disposição, já que o investidor obteve um percentual maior de ganhos do que de perdas. As fórmulas referentes às variáveis são apresentadas em 1, 2 e 3.

$$
\begin{gathered}
\frac{G R_{i}}{G R_{i}+G N R_{i}}=P G R_{i} \\
\frac{P R_{i}}{P R_{i}+P N R_{i}}=P P R_{i} \\
C D_{i}=P G R_{i}-P P R_{i}
\end{gathered}
$$

Nas fórmulas, GR representa ganhos realizados, GNR equivale a ganhos não realizados, PR corresponde a perdas realizadas e PNR a perdas não realizadas. Especificamente, nas fórmulas 1 e 2, para o cálculo da proporção de ganhos (perdas) é feita a divisão dos ganhos (perdas) pela soma dos ganhos (perdas) realizados com os não realizados. Nos períodos em que um investidor individual ou institucional vendeu um ativo com o preço superior (inferior) ao preço de compra, foi computado um ganho (perda) realizado. Ainda, considerou-se um ganho 
(perda) não realizado a cada vez em que o investidor deixou de realizar um ganho (perda) para cada ativo (ODEAN, 1998).

Quanto à análise dos dados, empregou-se o mesmo método utilizado por Da Costa Jr. et al. (2013), isto é, análise agregada, que considera cada um dos grupos como um todo, e análise individual, que calcula o efeito disposição separadamente para cada investidor, sendo calculado o CD (Fórmula 3) para ambos os casos. Ademais, foram realizados testes de hipóteses, estabelecendo-se hipóteses nulas (H0) e suas hipóteses alternativas (H1), apresentadas a seguir, e aplicados os testes paramétrico $t$ de Student (Fórmula 4), de diferenças de média, e nãoparamétrico Mann-Whitney (Fórmula 5), de diferenças de mediana, para testá-las, cujo grau de significância foi definido pelo $p$-valor, sendo significativos os resultados inferiores a $5 \%$.

$$
\begin{gathered}
t=\frac{\left(\bar{X}-\mu_{0}\right)}{s / \sqrt{n}} \\
U_{1}=n_{1} n_{2}+\frac{n_{1}\left(n_{1}+1\right)}{2}-R_{1} \\
U_{2}=n_{1} n_{2}+\frac{n_{2}\left(n_{2}+1\right)}{2}-R_{2}
\end{gathered}
$$

Em (4), $\bar{X}$ representa a média da amostra, $\mu_{0}$ é a média hipotética da população, $s$ é o desvio padrão da amostra e $n$ é o tamanho da amostra. Em (5), $U_{1}$ é o teste U para a primeira amostra, $U_{2}$ é o teste $\mathrm{U}$ para a segunda amostra, $n_{1}$ e $n_{2}$ são os tamanhos da primeira e segunda amostras, e $R_{1}$ e $R_{2}$ são a soma das fileiras das observações da primeira e segunda amostras.

Inicialmente, testou-se o efeito disposição no nível agregado, sendo que a hipótese H0 é não rejeitada quando o $\mathrm{CD}$ é igual ou menor a zero, e a hipótese H1 é não rejeitada quando o CD é maior do que zero, isto é: $H O: C D=\langle 0$ e $H 1: C D>0$. Estas hipóteses foram testadas através do teste $t$, calculado com base nos resultados encontrados nas Fórmulas 1 e 2, levando-se em conta também o erro padrão (SE).

$$
t=\frac{P G R_{i}-P P R_{i}}{S E_{i}}
$$

Na qual:

$$
S E=\sqrt{\frac{P G R_{i}\left(1-P G R_{i}\right)}{G R_{i}+G N R_{i}}+\frac{P P R_{i}\left(1-P P R_{i}\right)}{P R_{i}+P N R_{i}}}
$$


Na sequência, em relação ao efeito disposição no nível individual, assumiu-se que a hipótese H0 é não rejeitada caso o CD individual for igual ao CD institucional, e que a hipótese H1 é não rejeitada quando o $\mathrm{CD}$ individual for maior do que o $\mathrm{CD}$ institucional, ou seja: $H O$ : CD_individual=CD_institucional, e H1:CD_individual>CD_institucional. Estas hipóteses foram testadas pelos testes $t$ e de Mann-Whitney, os quais foram realizados para cada ação, sendo comparado o efeito disposição dos investidores pessoa física com o efeito disposição dos investidores institucionais. Para estes testes, definiu-se as opções unicaudal com variação heterocedástica, de forma a garantir com que os resultados dos testes fossem superiores a zero.

Os dois testes também foram aplicados para comparar os retornos individuais e institucionais, sendo considerado na hipótese H0 que os retornos individuais são iguais aos retornos institucionais, enquanto a hipótese $\mathrm{H} 1$ considera que os retornos individuais são diferentes dos institucionais. Assim, HO: ret_individual=ret_institucional, e H1: ret_individual $\neq$ ret_institucional. Para os testes nesse caso, optou-se pelas opções bicaudal com variação heterocedástica, visto que não se tinha conhecimento se os resultados seriam superiores a zero. Ainda, foram analisadas as médias dos retornos totais para cada tipo de ação e de cada tipo de investidor. Primeiro, somou-se todos os retornos das operações de acordo com o seu tipo e dividiu-se pela quantia total de operações, conforme apresentado na Fórmula 8.

$$
(\text { Retorno Médio })=\frac{\sum_{i=0}^{n} r e t_{i}}{n}
$$

Na Fórmula 8, $\sum_{i=0}^{n}$ ret representa a somatória de todos os retornos, enquanto $n$ é a quantidade de operações realizadas. Na sequência, calculou-se a média dos retornos por investidor, a partir da Fórmula 9.

$$
r e t_{i}=\ln \frac{P V}{P M C}
$$

Nessa fórmula, ret $_{i}$ exprime a média dos retornos por investidor, ao passo que o cálculo envolve a determinação do logaritmo natural $(\ln )$ da divisão entre o preço de venda das ações (PV) e o preço médio de compra (PMC), o qual foi ponderado pelas quantidades compradas e pelos respectivos preços em cada compra adicional, adotando-se o critério First In, First Out $(F I F O)$. 


\section{APRESENTAÇÃO E ANÁLISE DOS RESULTADOS}

A seguir, é feita a apresentação e análise dos resultados obtidos na pesquisa, sendo que a análise dos resultados foi realizada a partir do modelo proposto por Da Costa Jr. et al. (2013), o qual explora os resultados agregados e individuais. Inicialmente, são apresentados na Tabela 2 os resultados para a análise do efeito disposição agregado.

\section{Tabela 2 - $\mathrm{O}$ efeito disposição agregado para os dois tipos de investidores, geral e por} ação

\begin{tabular}{|c|c|c|c|c|c|c|c|c|}
\hline \multirow{2}{*}{ Variáveis } & \multicolumn{2}{|c|}{ Geral } & \multicolumn{2}{|c|}{ BBDC4 } & \multicolumn{2}{|c|}{ ABEV3 } & \multicolumn{2}{|c|}{ LAME4 } \\
\hline & Inv. Inst. & Inv. Ind. & Inv. Inst. & Inv. Ind. & Inv. Inst. & Inv. Ind. & Inv. Inst. & Inv. Ind. \\
\hline $\begin{array}{l}\text { Quantidade de } \\
\text { Investidores }\end{array}$ & 30 & 30 & 30 & 30 & 30 & 30 & 30 & 30 \\
\hline GR & 1359 & 194 & 305 & 75 & 111 & 75 & 943 & 44 \\
\hline PR & 1038 & 121 & 192 & 41 & 202 & 57 & 644 & 23 \\
\hline GNR & 67600 & 3953 & 17898 & 1422 & 6102 & 1256 & 43600 & 1275 \\
\hline PNR & 54795 & 4634 & 16498 & 1137 & 8247 & 1896 & 30050 & 1601 \\
\hline PGR & 0,0197 & 0,0468 & 0,0168 & 0,0501 & 0,0179 & 0,0563 & 0,0212 & 0,0334 \\
\hline PPR & 0,0186 & 0,0254 & 0,0115 & 0,0348 & 0,0239 & 0,0292 & 0,0210 & 0,0142 \\
\hline $\mathrm{CD}$ & 0,0011 & 0,0213 & 0,0053 & 0,0153 & $-0,0060$ & 0,0272 & 0,0002 & 0,0192 \\
\hline $\begin{array}{l}\text { Teste } t \\
(\mathrm{H} 1: \mathrm{CD}>0)\end{array}$ & 1,4320 & 5,3380 & 4,1695 & 1,9696 & $-2,5565$ & 3,6808 & 0,1777 & 3,3394 \\
\hline p-valor & 0,1429 & $\mathbf{0 , 0 0 0} * * *$ & $0,0000 * * *$ & $\mathbf{0 , 0 5 7 3} * *$ & $0,0152 * * *$ & $0,0004 * * *$ & 0,3927 & $0,0015 * * *$ \\
\hline
\end{tabular}

Nota. Inv. Inst.=investidores institucionais; Inv. Ind.=investidores individuais; GR=ganhos realizados; $\mathrm{PR}=$ perdas realizadas; GNR=ganhos não realizados; PNR=perdas não realizadas; PGR=proporção de ganhos realizados; $\mathrm{PPR}=$ proporção de perdas realizadas; $\mathrm{CD}=$ coeficiente de disposição. **Significativo a $5 \%$. $* * *$ Significativo a $1 \%$.

A partir da Tabela 2, percebe-se que na análise dos dados agregados, isto é, ao se considerar cada um dos grupos como um todo, o coeficiente de disposição foi positivo tanto para os investidores institucionais $(\mathrm{CD}=0,0011)$ quanto para os investidores individuais $(C D=0,0213)$, o que confirmaria a presença do efeito disposição para os dois grupos. No entanto, procedeu-se aos testes de hipóteses pelo teste $t$, considerando a hipótese nula (H0) de que o coeficiente de disposição é igual a zero e a hipótese alternativa (H1) de que o coeficiente de disposição é superior a zero. Para esta análise, o $p$-valor demonstrou que a presença do coeficiente de disposição para os investidores institucionais não foi significativa, ao passo que apresentou significância ao nível de $1 \%$ para os investidores individuais, sendo favorável ao argumento que o efeito disposição está presente mais frequentemente nos investidores individuais do que nos institucionais, tendo-se a não rejeição da hipótese H1.

Adicionalmente, optou-se por analisar o efeito disposição agregado para cada uma das ações adotadas na amostra. Conforme exposto na Tabela 2, os resultados para a ação BBDC4 mostram que os valores para o $\mathrm{CD}$ em ambos os grupos de investidores foram superiores à zero,

REAd | Porto Alegre - Vol. 27 - N. 1 - Janeiro / Abril 2021 - p. 210-231. 
o que foi confirmado pelo teste de hipóteses. Para o grupo de investidores institucionais, o teste $t$ obteve um p-valor significativo ao nível de $1 \%$, enquanto o nível de significância para os investidores individuais foi de 5\%. Assim, depreende-se que ambos os grupos apresentaram um efeito disposição significativo para esta ação, sendo mais relutantes em realizar perdas do que propícios a realizar ganhos.

A respeito da ação $\mathrm{ABEV} 3$, o valor do coeficiente de disposição para o grupo de investidores institucionais foi $(\mathrm{CD}=-0,006)$, demonstrando que o $\mathrm{CD}$ é negativo. Já para os investidores individuais, o coeficiente de disposição assumiu um valor positivo $(C D=0,0272)$. Quanto ao teste de hipóteses, o nível de significância do teste $t$ foi de $1 \%$ tanto para os investidores individuais quanto para os institucionais; no entanto, para esses últimos o valor negativo alcançado pelo teste $t$ reforça a ausência do efeito disposição.

Já para a ação LAME4, tanto o grupo de investidores institucionais quanto o de individuais apresentaram coeficientes de disposição positivos $(0,0002$ e $\quad 0,0192$ respectivamente). Entretanto, em relação ao teste de hipóteses, o teste $t$ para os investidores institucionais não se mostrou significativo, enquanto para o grupo de investidores individuais obteve-se um nível de significância de $1 \%$.

Com base nos resultados, verifica-se que o coeficiente de disposição alcançou um valor maior para o grupo de investidores individuais em todas as análises, sendo que o teste de diferença de média entre os grupos é apresentado na sequência, de modo a confirmar estatisticamente tal constatação. Ainda, a presença do CD foi significativa em todas as análises para o grupo de investidores individuais, ao passo que em dois casos não foi significativo para o grupo de investidores institucionais, e em um dos casos o próprio $\mathrm{CD}$ obteve um valor inferior a zero.

Tais resultados corroboram os achados de Locke e Mann (2000), os quais concluíram que investidores institucionais também estão sujeitos ao efeito disposição, sendo que aqueles com carteiras de investimentos que apresentavam retornos ruins tendiam a manter as ações perdedoras por mais tempo, assim como os achados de Rodrigues (2016), que, ao considerar gestores de fundos de investimento no Brasil, também confirmou a presença do efeito disposição. Ademais, em concordância com Zahera e Bansal (2019), foi perceptível que os investidores individuais são bastante suscetíveis à ocorrência do efeito disposição em seu padrão de comportamento, o que é comprovado pelo teste $t$ que indicou a presença significativa do efeito disposição em investidores individuais para todas as análises. Adicionalmente, a 
afirmação dos autores de que os investidores institucionais podem ou não apresentar o efeito disposição também é reforçada.

A etapa seguinte envolveu a análise do efeito disposição no nível individual, isto é, considerou-se o efeito disposição para cada investidor em particular. Ainda, verificou-se a diferença entre os retornos médios dos diferentes tipos de investidor. Os resultados obtidos a partir de tais análises são apresentados na Tabela 3.

Tabela 3 - O efeito disposição individual para cada tipo de investidor e de ação

\begin{tabular}{|c|c|c|c|c|}
\hline \multirow{2}{*}{ Variáveis } & \multicolumn{4}{|c|}{ Investidor Individual } \\
\hline & BBDC4 & ABEV3 & LAME4 & Média dos ativos \\
\hline Quantidade de Investidores & 19 & 28 & 15 & 21 \\
\hline Média dos retornos por investidor & 0,0107 & $-0,0083$ & $-0,0078$ & $-0,0018$ \\
\hline Desvio padrão dos retornos & 0,0592 & 0,0181 & 0,0468 & 0,0414 \\
\hline Máximo dos retornos & 1,5525 & 1,0851 & 1,3942 & 1,3439 \\
\hline Mínimo dos retornos & 0,7677 & 0,8818 & 0,8068 & 0,8187 \\
\hline Média do CD & 0,1071 & 0,0665 & 0,0933 & 0,0890 \\
\hline Desvio padrão - CD & 0,2405 & 0,2204 & 0,2703 & 0,2438 \\
\hline Investidores com $\mathrm{CD}>0$ & $68 \%$ & $54 \%$ & $67 \%$ & $63 \%$ \\
\hline \multirow{2}{*}{ Variáveis } & \multicolumn{4}{|c|}{ Investidor Institucional } \\
\hline & BBDC4 & ABEV3 & LAME4 & Média dos ativos \\
\hline Quantidade de Investidores & 28 & 28 & 26 & 27 \\
\hline Média dos retornos por investidor & 0,0109 & $-0,0033$ & 0,0331 & 0,0135 \\
\hline Desvio padrão dos retornos & 0,0561 & 0,0275 & 0,0503 & 0,0446 \\
\hline Máximo dos retornos & 1,5736 & 4,9179 & 1,5511 & 2,6809 \\
\hline Mínimo dos retornos & 0,7102 & 0,8671 & 0,7132 & 0,7635 \\
\hline Média dos CD & 0,0133 & $-0,0398$ & 0,0307 & 0,0014 \\
\hline Desvio padrão - CD & 0,0306 & 0,0966 & 0,1272 & 0,0848 \\
\hline Investidores com $\mathrm{CD}>0$ & $71 \%$ & $32 \%$ & $65 \%$ & $56 \%$ \\
\hline Teste $t$ (H1:CD_indiv.>CD_inst.) & 1,6914 & 2,3112 & 0,8438 & 1,6155 \\
\hline p-valor & $\mathbf{0 , 0 5 3 8 * *}$ & $0,0132 * * *$ & 0,2050 & 0,0907 \\
\hline Teste $M-W$ (H1:CD_indiv.>CD_inst.) & 1,6802 & 1,8355 & 1,2315 & 1,5824 \\
\hline p-valor & $0,0466 * *$ & $0,0325 * *$ & 0,1105 & 0,0632 \\
\hline Teste $t$ (H1:Ret_indiv. $\neq$ Ret_inst.) & 0,0085 & 0,8039 & 2,6194 & 1,1439 \\
\hline $\mathrm{p}$-valor & 0,9933 & 0,4255 & $0,0135 * *$ & 0,4774 \\
\hline Teste $M$ - $W$ (H1:Ret_indiv. $\neq$ Ret._inst.) & 0,2493 & 1,1553 & 2,9908 & 1,4651 \\
\hline p-valor & 0,8051 & 0,2501 & $0,0021 * * *$ & 0,3524 \\
\hline
\end{tabular}

Nota. $C D=$ coeficiente de disposição; $C D \_$indiv.=coeficiente de disposição individual; CD_inst.=coeficiente de disposição institucional; Teste $M$ - $W=$ Teste Mann-Whitney; Ret_indiv.=retornos individuais; Ret_inst.=retornos institucionais. $* *$ Significativo a $5 \%$. $* * *$ Significativo a $1 \%$.

Como é possível observar na Tabela 3, a quantidade de investidores participantes nos testes foi inferior a 30, quantia inicial de investidores para cada tipo de ativo. Esta redução na amostra se deve ao fato de que, no cálculo do $\mathrm{CD}$, o teste $t$ e o p-valor obtiveram valores nulos para alguns investidores, visto que o GR e o GNR ou a PR e a PNR eram nulos simultaneamente. Assim, tais investidores foram retirados do cálculo da média individual do $\mathrm{CD}$ e dos retornos, assim como do teste $t$ e teste Mann-Whitney. 
A respeito dos resultados apresentados na Tabela 3, percebe-se que em média $63 \%$ dos investidores individuais apresentaram o efeito disposição, considerando a média dos ativos. Para cada ativo em particular, $68 \%$ dos investidores individuais apresentou CD para a ação BBDC4, 54\% para o ativo ABEV3, e 67\% para a ação LAME4. Em relação aos investidores institucionais, $56 \%$ destes apresentaram efeito disposição, ao se analisar a média dos três ativos. Tal percentual foi de $71 \%$ ao se considerar apenas a ação BBDC4, 32\% para o ativo ABEV3 e $65 \%$ para LAME4.

Na sequência, destacam-se as médias do $\mathrm{CD}$, ou seja, a magnitude do efeito disposição para cada classe de investidor. Para os investidores individuais, a média do CD em relação aos três ativos foi de 0,0890, ao passo que alcançou valores de $0,1071,0,0665$ e 0,0933 para as ações BBDC4, ABEV3 e LAME4, respectivamente, sendo perceptível um efeito disposição superior frente ao ativo BBDC4. Já para os investidores institucionais, o CD obteve média de 0,0014 frente aos três ativos, enquanto obteve valores de $0,0133,-0,0398$ e 0,0307 para os ativos BBDC4, ABEV3 E LAME4. Novamente, percebe-se que a magnitude do efeito disposição é maior para os investidores individuais do que para os institucionais.

No entanto, é necessário que tal afirmação seja testada estatisticamente. Para isso, realizou-se os testes $t$ e Mann-Whitney, considerando-se a hipótese H1 de que o CD dos investidores individuais é superior ao dos investidores institucionais. Em relação ao teste $t$, este foi significativo em dois casos, sendo que para o ativo BBDC4 obteve-se nível de significância de 5\%, e para o ativo ABEV3 a significância foi de 1\%. Os resultados foram similares para o teste de Mann-Whitney, em que tanto para BBDC4 quanto para ABEV3 obteve-se nível de significância de 5\%. Os testes para o ativo LAME4 não foram significativos. Assim, tem-se a não rejeição da hipótese alternativa (H1), e assume-se que realmente os investidores individuais apresentam um nível de efeito disposição superior, com médias e medianas maiores do que a dos investidores institucionais, para duas das ações analisadas na pesquisa

Os resultados encontrados vão ao encontro de Shapira e Venezia (2001), os quais argumentaram que investidores institucionais tendem a ser mais racionais em seu processo de tomada de decisão, o que levaria à menor presença de vieses comportamentais, como o efeito disposição. Já Cici (2005) percebeu que o efeito disposição afeta alguns fundos de investimento, porém em menor magnitude do que os individuais, assim como Prates, Da Costa Jr. e Santos (2019) constataram que os investidores pessoa física têm maior propensão ao efeito disposição, enquanto investidores institucionais não apresentaram resultados condizentes com este viés comportamental.

REAd | Porto Alegre - Vol. 27 - N.o 1 - Janeiro / Abril 2021 - p. 210-231. 
Quanto às médias dos retornos, os investidores individuais obtiveram em média retorno negativo de $0,18 \%$ em relação à média geral dos ativos. Em relação à cada ação, os retornos foram de $1,07 \%$ frente ao ativo BBDC4, - $0,83 \%$ referente ao ativo ABEV3 e - $0,78 \%$ quanto ao ativo LAME4, ou seja, retornos negativos para esses dois ativos. A respeito dos retornos para os investidores institucionais, a média de seus retornos foi de 1,35\% considerando a média dos ativos, $1,09 \%$ relativo à ação BBDC4, $-0,33 \%$ quanto ao ativo ABEV3, também um retorno negativo, e de 3,31\% referente ao ativo LAME4. Percebe-se, então, que a média dos retornos dos investidores institucionais é superior à média dos investidores individuais, sugerindo a maior eficiência dos investimentos realizados por investidores institucionais, uma vez que contam com especialistas para definir e administrar suas carteiras de ativos. Os valores máximos também comprovam esta afirmação, visto que todos os máximos dos investidores institucionais são superiores aos dos investidores individuais.

Por fim, aplicou-se também os testes $t$ e Mann-Whitney para os retornos médios dos ativos, sendo a hipótese alternativa (H1) de que os retornos médios individuais são diferentes dos retornos médios institucionais. No teste $t$, os resultados apontam significância apenas no caso da ação LAME4, para a qual o teste apresentou nível de significância de 1\%, ou seja, apenas neste caso a hipótese H1 não foi rejeitada. Assim, verifica-se que a diferença mais significativa na média dos retornos de um ativo está na ação LAME4, enquanto os ativos BBDC4 e ABEV3 têm diferença não significativa na média do retorno das aplicações. O mesmo ocorreu quanto ao teste de Mann-Whitney, o qual foi significativo apenas para LAME4, com significância de 1\%. A diferença dos retornos obtidos pelos investidores individuais e institucionais, e os maiores retornos médios e medianos obtidos por esses últimos podem ser justificados pela mesma linha de raciocínio de Shapira e Venezia (2001), segundo os quais os investidores institucionais possuem ferramentas de análise que apoiam o processo de tomada de decisão, o que tende a garantir retornos maiores em suas carteiras.

A partir dos resultados apresentados, de maneira geral, é possível crer que o coeficiente de disposição mais elevado para os investidores individuais esteja relacionado aos diferentes componentes do efeito disposição. Por exemplo, o comportamento apresentado na teoria da perspectiva de Kahneman e Tversky, que consiste na inclinação dos investidores a conservarem ações que estão perdendo valor, visto que a dor de uma perda adicional é inferior ao prazer de eventualmente reaver o valor de compra, como explicado por Weber e Camerer (1998), pode ser mais acentuado nos investidores individuais do que nos institucionais.

O mesmo pode ser pensado para a contabilidade mental, de Thaler (1985), segundo o qual os agentes têm dificuldade em fechar contas mentais com perdas, já que isso significaria a 
realização da perda; assim, mantém os ativos perdedores em suas carteiras. Como exposto anteriormente, os investidores institucionais tendem a se comportar de maneira mais racional no processo de tomada de decisão; desta forma é possível que estes não apresentem tanto orgulho ou aversão arrependimento quanto investidores individuais, conceitos estes apresentados por Muermann e Volkman (2006).

Ainda, existe a possibilidade que a reversão à media, evidenciada por Odean (1998), seja mais saliente em investidores individuais, consistindo na esperança que os investimentos depreciados venham a se valorizar, ao passo que aqueles com apreciação significativa sejam depreciados, de forma que os preços médios dos ativos se dirijam a um valor médio. Este viés comportamental está ligado aos retornos das carteiras, uma vez que Odean (1998) constatou que as ações vencedoras acabaram apresentando retornos médios superiores aos das ações perdedoras mantidas por um longo tempo, o que pode justificar os retornos mais elevados alcançados pelos investidores institucionais, que não mantém tantas ações perdedoras (ou não apresentam um efeito disposição elevado) como os investidores individuais.

\section{CONSIDERAÇÕES FINAIS}

A presente pesquisa teve como foco o efeito disposição, um viés comportamental verificado em operações feitas no mercado financeiro. Agentes sob a influência deste viés estão mais inclinados a manterem ativos financeiros que geram prejuízos do que ativos que trazem retornos positivos, sendo que as primeiras reflexões sobre este viés foram apresentadas por Shefrin e Statman (1985). Assim, estabeleceu-se como objetivo verificar se existem diferenças frente a presença do efeito disposição na tomada de decisões financeiras entre investidores individuais e institucionais atuantes na bolsa de valores brasileira. Autores como Shapira e Venezia (2001) verificaram que os investidores institucionais estão mais propícios a decisões racionais, uma vez que têm à sua disposição mais informações e ferramentas analíticas do que investidores pessoa física, ao passo que Cici (2005) averiguou que o efeito disposição afeta, sim, fundos de investimentos; no entanto, em menor grau do que influencia o comportamento decisório dos investidores individuais.

Por meio da análise de uma amostra obtida a partir de dados de transações reais executadas na bolsa de valores brasileira durante o período de 2 de fevereiro de 2012 a 31 de outubro de 2014, e envolvendo investidores individuais e institucionais, no caso, fundos mútuos, e três diferentes ações, e pelo uso da metodologia exposta em Odean (1998) e em Costa Jr. et al. (2013), foi possível identificar a presença do coeficiente de disposição, nos níveis 
agregado e individual. Na análise agregada, o coeficiente disposição se mostrou positivo para os investidores individuais nos três ativos estudados, enquanto que para os investidores institucionais o viés comportamental foi identificado para a maioria das ações, excetuando-se a ABEV3. É importante salientar que o grau do efeito disposição foi maior para os investidores individuais, reforçando os achados predominantes na literatura. Ainda, observou-se que a média dos retornos dos investimentos colhidos pelos investidores institucionais excederam a média dos retornos obtidos pelos investidores individuais; no entanto, uma diferença significativa foi percebida apenas frente ao ativo LAME4.

O maior efeito disposição encontrado para os investidores individuais pode ser consequência da falta de experiência dos mesmos ou de seu pouco conhecimento técnico a respeito do mundo dos investimentos. No lado oposto, investidores institucionais contam com mais ferramentas de análise e especialistas na área, o que pode mitigar o viés em suas decisões. Desta forma, diversas instituições brasileiras, como a Associação Brasileira das Entidades dos Mercados Financeiro e de Capitais (ANBIMA) e a Comissão de Valores Mobiliários (CVM), podem se mobilizar e incentivar os investidores pessoa física a realizarem treinamentos sobre o mercado financeiro, além de disponibilizarem materiais e cursos sobre economia comportamental. A partir dessa formação adicional, os investidores podem conhecer e entender os diferentes vieses comportamentais que afetam suas decisões, como o efeito disposição, a propensão ao risco e o excesso de confiança, e, assim passar a adotar um comportamento menos enviesado, permitindo que a tomada de decisões no ambiente de investimentos seja mais acertada.

Foram encontradas algumas limitações durante a execução da pesquisa, como a quantidade de ativos e de indivíduos considerados na amostra. Apesar da amostra ser relativamente grande quanto ao número de operações, estas podem não representar o mercado como um todo, uma vez que foram utilizadas apenas ações de grande negociabilidade e de companhias com alto valor de mercado. Por fim, uma proposta para pesquisas futuras envolve a ampliação da amostra, com a inclusão de diferentes investidores, seja eles individuais, com maior ou menor experiência de investimento em bolsas de valores, ou institucionais, de maior ou menor grau de assertividade frente a realização de investimentos. Ademais, de forma a avançar na literatura e cobrir possíveis lacunas teóricas, sugere-se explorar separadamente os efeitos exercidos pelos vieses comportamentais considerados como formadores do efeito disposição, como a contabilidade mental, a aversão ao arrependimento e o auto-controle, de forma a melhor compreender o mercado e o padrão de comportamento dos agentes financeiros. 


\section{REFERÊNCIAS}

ANDREASSEN, P. Explaining the price-volume relationship: The difference between price changes prices. Organizational Behavior and Human Decision Processes, v. 41, n. 3, p. 371-389, 1998.

B3. Histórico pessoas físicas. Set. 2020. Disponível em: http://www.b3.com.br/pt br/marketdata-e-indices/servicos-de-dados/market-data/consultas/mercado-a-vista/historico-pessoasfisicas/. Acesso em: 09 out. 2020.

BERNOULLI, D. Exposition of a new theory on the measurement of risk. Econometrica, v. 22, n. 1, p. 23-36, 1954.

BOGEA, F.; BARROS, L. A. B. C. Processo de tomada de decisão do investidor individual brasileiro no mercado acionário nacional: um estudo exploratório enfocando o efeito disposição e os vieses da ancoragem e do excesso de confiança. Gestão \& Regionalidade, v. 24, n. 71, p. 6-18, 2008.

BRAV, A.; HEATON, J. B. Testing behavioral theories of undervaluation and overvaluation. Kellogg School of Management, 2006. Disponível em http://www.kellogg.northwestern.edu Acesso em: 20 Nov. 2019.

CHEN, G. M.; et al. Trading performance, disposition effect, overconfidence, representativeness bias, and experience of emerging market investors. Journal of Behavioral Decision Making, v. 20, n. 4, p. 425-451, 2007.

CICI, G. The relation of the disposition effect to mutual funds trade and performance. Working Paper, College of Willian and Mary, Manson of School of Business, 2005.

Disponível em: http://papers.ssrn.com/sol3/papers.cfm?abstract_id=645841 Acessado em 14 jan. 2020.

CICI, G. The prevalence of the disposition effect in mutual funds' trades. The Journal of Financial and Quantitative Analysis, v. 47, n. 4, p. 795-820, 2012.

DA COSTA JR, N. C. A.; et al. Efeito disposição e experiência no mercado financeiro. Revista de Economia e Administração, v. 6, n. 4, p. 447-463, 2007.

DA COSTA JR, N. C. A.; et al. The disposition effect and investor experience. Journal of Banking and Finance, v. 37, n. 5, p. 1669-1675, 2013.

DEAVES, R.; KLUGER, B.; MIELE, J. An exploratory experimental analysis of pathdependent investment behaviors. Journal of Economic Psychology, v. 67, p. 47-65, 2018.

EDWARDS, W. The theory of decision making. Psychological Bulletin, v. 51, n. 4, p. 380417, 1954.

GRINBLATT, M.; KELOHARJU, M. What makes investors trade? The Journal of Finance, v. 56, n. 2, p. 589-616, 2001. 
KAHNEMAN, D.; TVERSKY, A. Prospect theory: An analysis of decision under risk. Econometrica, v. 47, n. 2, p. 263-292, 1979.

LOCKE, P.; MANN, S. Do professional traders exhibit loss realization aversion? Working Paper, The George Washington University and Texas Christian University, 2000. Disponível em:

https://jamesgoulding.com//Research_II/Psychology/Psychology\%20(Locke\%20and\%20Man n).pdf Acesso em: 03 mar. 2020.

MUERMANN, A.; VOLKMAN, J. M. Regret, pride, and the disposition effect. PARC Working Paper Series, University of Pennsylvania, 11, 2006. Disponível em: https://repository.upenn.edu/cgi/viewcontent.cgi?article=1010\&context=parc_working_paper s Acesso em: 02 mar. 2020.

ODEAN, T. Are investors reluctant to realize their losses? The Journal of Finance, v. 53, n. 5, p. 1775-1798, 1998.

PLONER, M. Hold on to it? An experimental analysis of the disposition effect. Judgment and Decision Making, v. 12, n. 2, p. 118-127, 2017.

PRATES, W. R.; DA COSTA JR., N. C. A.; SANTOS, A. A. P. Efeito disposição: Propensão à venda de investidores individuais e institucionais. Revista Brasileira de Economia, v. 73, n. 1, p. 97-119, 2019.

RIBEIRO, M. A.; CARVALHO JR, C. V. O.; DA ROCHA, J. S. A influência do efeito disposição nas decisões individuais de investimento. Revista Universo Contábil, v. 11, n. 3, p. 63-84, 2015.

RODRIGUES, M. R. O efeito disposição na indústria brasileira de fundos de investimento em ações: um estudo empírico sobre os gestores brasileiros. 54 p. Dissertação (Mestrado em Administração), Pontifícia Universidade Católica de São Paulo, São Paulo, 2016.

SAKATE, M. Pessoa física já negocia na Bolsa o equivalente ao volume de fundos e bancos. CNN Brasil Business, São Paulo, 25 jun. 2020. Disponível em:

https://www.cnnbrasil.com.br/business/2020/06/25/pessoa-fisica-ja-negocia-na-bolsa-oequivalente-ao-volume-de-fundos-e-bancos. Acesso em: 09 out. 2020.

SHAPIRA, Z.; VENEZIA, I. Patterns of behavior of professional managed and independent investors. Journal of Banking and Finance, v. 25, n. 8 p.777-790, 1985.

SHEFRIN H.; STATMAN, M. The disposition to sell winners too early and ride losers too long: Theory and evidence. The Journal of Finance, v. 40, n. 3, p. 777-790, 1985.

SHILLER, R. J. From efficient markets theory to behavioral finance. Journal of Economic Perspectives, v. 17, n. 1, pp. 83-104, 2003.

THALER, R. Mental accounting and consumer choice. Marketing Science, v.4, p. 199-124, 1985. 
THALER, R.; SHEFRIN, M. An economic theory of self-control. Journal of Political Economy, v. 89, n.2, p. 392-406, 1981.

TIZZIANI, E. et al. O efeito disposição na indústria brasileira de fundos de investimento em ações. Revista Brasileira de Finanças, v. 8, n. 4, p. 383-416, 2010.

VON NEUMANN, J.; MORGENSTERN, O. Theory of games and economic behavior. $3^{\text {a }}$. ed. Princeton: Princeton University Press, 1953.

WEBER, M.; CAMERER, C. F. The disposition effect in securities trading: an experimental analysis. Journal of Economic Behavior \& Organization, v. 33. p. 167-184, 1998.

ZAHERA, S. A.; BANSAL, R. A study of prominence for disposition effect: a systematic review. Qualitative Research in Financial Markets, v. 11, n. 1, p. 2-21, 2019. 